\title{
Hemoglobin Himeji and inconsistent hemoglobin A1c values: a case report
}

Vânia Guedes ${ }^{1 *}$, Rita Bettencourt-Silva ${ }^{2,3}$, Joana Queirós ${ }^{2}$, Maria da Luz Esteves ${ }^{4}$, Maria José Teles ${ }^{5}$ and Davide Carvalho 2,3

\begin{abstract}
Background: Hemoglobin A1c is used to evaluate the glycemic control in patients with diabetes and is a risk marker for chronic complications of diabetes. Hemoglobin variants are reported to falsely lower or increase hemoglobin A1c test results. We present a case report of a patient with diabetes with discrepancy between fasting plasma glucose and hemoglobin A1c due to the presence of hemoglobin Himeji, a clinically silent and very rare hemoglobinopathy.

Case presentation: A 76-year-old white woman, born and living in Portugal, with type 2 diabetes presented to the family physician for a routine visit. She had no active complaints, including history or symptoms of hypoglycemia, and her physical examination was unremarkable. A review of her laboratory data showed fasting plasma glucose of $190 \mathrm{mg} /$ $\mathrm{dL}$ and a hemoglobin A1c of $4.1 \%$. The remaining blood test results were clinically insignificant; a further review of her laboratory data over the past 4 years revealed that her fasting plasma glucose had ranged from 130 to $250 \mathrm{mg} / \mathrm{dL}$ and hemoglobin A1c was consistently lower than 5\%. A study of hemoglobins detected 32.8\% of abnormal hemoglobin. Genetic sequencing identified a heterozygous mutation compatible with hemoglobin Himeji (c.422C>A; p.Ala141Asp). We tracked her family (three sons, six grandchildren, and two greatgrandchildren) for the presence of this hemoglobin variant, but none had this hemoglobinopathy.

Conclusions: Despite the advantages of hemoglobin A1c in the follow-up and treatment of diabetes, the factors that interfere with its results must be known to ensure a correct estimation of the degree of glycemic control and a proper management of the disease. Therefore, health professionals should suspect the existence of hemoglobin variants when: the hemoglobin A1c value is above $15 \%$ or below the lower limit of its reference interval; there is a significant modification in its result coinciding with a change in assay methods; and there is a low correlation between plasma glucose and hemoglobin A1c. In patients with hemoglobin Himeji, alternate ways of monitoring glycemic control (fructosamine or glycated serum albumin) should be used.
\end{abstract}

Keywords: Diabetes mellitus, Hemoglobin A1c, Hemoglobinopathies, Mutations, Hemoglobin Himeji

\section{Background}

Glycated hemoglobin ( $\mathrm{Hb}) \mathrm{A} 1 \mathrm{c}(\mathrm{HbA1c})$ is a term used to describe $\mathrm{Hb}$ that has been irreversibly linked to glucose through a nonenzymatic reaction $[1,2]$. HbA1c testing is used to document the degree of glycemic control in patients with diabetes mellitus, because its value reflects the mean glycemia of the last 120 days, the erythrocyte lifespan average [3]. It is also useful to determine the risk for the development and progression of complications related to this chronic disease $[1,2]$.

\footnotetext{
* Correspondence: vaniapoguedes@gmail.com

${ }^{1}$ Family Medicine, Unidade de Saúde Familiar Faria Guimarães, Rua Faria

Guimarães 915/931, 4200-292 Porto, Portugal

Full list of author information is available at the end of the article
}

Several assay methods, certified by the National Glycohemoglobin Standardization Program (NGSP) and calibrated to the Diabetes Control and Complications Trial (DCCT) reference, can be used to determine HbA1c value $[1,2,4]$. However, several factors can interfere with various methods, affecting the accuracy of their measurements $[1,2,5,6]$. $\mathrm{Hb}$ variants are reported to falsely lower or increase HbA1c test results $[7,8]$. We present a case report of a patient with diabetes with discrepancy between fasting plasma glucose (FPG) and $\mathrm{HbA1c}$, due to the presence of $\mathrm{Hb}$ Himeji, a clinically silent and very rare hemoglobinopathy. 


\section{Case presentation}

A 76-year-old white woman born and living in Portugal had a medical history of type 2 diabetes mellitus (without known microvascular or macrovascular complications) for more than 15 years, as well as hypertension, hyperlipidemia, and depression. She was treated with metformin (1500 mg per day), losartan/hydrochlorothiazide (100/ $25 \mathrm{mg}$ per day), simvastatin (20 mg per day), aspirin (100 mg per day), and trazodone (150 mg per day).

She presented to the family physician for a routine visit. She had no active complaints, including history or symptoms of hypoglycemia. At the time of the evaluation, her physical examination was unremarkable, including her body mass index $\left(24.3 \mathrm{~kg} / \mathrm{m}^{2}\right)$. A review of her laboratory data showed a FPG of $190 \mathrm{mg} / \mathrm{dL}$ and an HbAlc of 4.1\%, which was measured by high-performance liquid chromatography (HPLC). The remaining blood test results were clinically irrelevant, including complete blood count (Table 1), lipid profile, liver and kidney functions, and iron metabolism. Inconsistent results were confirmed by analytical reassessment of HbA1c (4.5\%, by HPLC) and FPG $(236 \mathrm{mg} / \mathrm{dL})$. Further review of her laboratory data over the past 4 years revealed that FPG had ranged from 130 to $250 \mathrm{mg} / \mathrm{dL}$ and $\mathrm{HbA} 1 \mathrm{c}$ was consistently lower than $5 \%$.

Given this discrepancy between HbA1c and plasma glucose, we hypothesized that she had an abnormal $\mathrm{Hb}$, after excluding other potential factors such as anemia, hypertriglyceridemia, uremia, and chronic alcoholism [2]. Therefore, $\mathrm{Hb}$ variants were studied after obtaining informed consent. Hb electrophoresis showed an abnormal peak $(32.8 \%)$ with an earlier retention time than for A0, suggesting the presence of an $\mathrm{Hb}$ variant (Fig. 1). The genetic sequencing of the beta-globulin gene revealed heterozygosity for the mutation c. $422 \mathrm{C}>\mathrm{A}$ (p.Ala141Asp) (p.Ala140Asp on the old nomenclature), corresponding to $\mathrm{Hb}$ Himeji.

Despite her denial of a relevant family history, namely of hematological diseases, we tracked her family (three sons, six grandchildren, and two greatgrandchildren) for the presence of this $\mathrm{Hb}$ variant, after obtaining informed

Table 1 Blood count

\begin{tabular}{lll}
\hline & Results & Reference values \\
\hline Hemoglobin $(\mathrm{g} / \mathrm{dL})$ & 15.0 & $12.0-16.0$ \\
Erythrocytes $\left(\times 10^{12} / \mathrm{L}\right)$ & 4.90 & $4.0-5.0$ \\
Hematocrit $(\%)$ & 44.2 & $37-49$ \\
Reticulocyte count & & \\
$\quad$ Percentage $(\%)$ & 2.1 & $0.2-2.0$ \\
Absolute value $\left(\times 10^{9} / \mathrm{L}\right)$ & 105.6 & $50.0-100.0$ \\
Low fluorescence reticulocyte $(\%)$ & 90.6 & \\
$\quad$ Medium fluorescence reticulocyte $(\%)$ & 8.6 & \\
High fluorescence reticulocyte $(\%)$ & 0.8 & \\
\hline
\end{tabular}

consent. The study of $\mathrm{Hb}$ by HPLC was normal in all of them. Unfortunately, her two brothers were not available for study and her parents had died.

\section{Discussion}

Currently more than $1200 \mathrm{Hb}$ variants have been reported worldwide [9]. The most frequent are $\mathrm{HbS}$ and $\mathrm{HbC}$ and the majority arises from point mutations in the $\mathrm{Hb}$ chains [7]. Approximately $80 \%$ of hemoglobinopathies are asymptomatic, whereas the remaining $20 \%$ are associated with hemolytic anemia, polycythemia, or methemoglobinemia $[7,8,10]$. With the widespread determination of HbA1c, the identification of $\mathrm{Hb}$ variants that are clinically silent has increased in the last years $[7,10]$.

$\mathrm{Hb}$ variants interfere with several assay methods of HbA1c $[2,7]$. Depending on the method, the same variant can produce unexpectedly high or low HbA1c values compared to glycemic control [2,7]. Boronate affinity chromatography is generally considered to be less affected by abnormal Hbs [2]. Manual review of most cation-exchange chromatograms can also alert to the presence of aberrant peaks produced by a variant [2]. Furthermore, in the vast majority of patients heterozygous for an abnormal $\mathrm{Hb}$, an appropriate method can be selected to accurately measure HbA1c [2]. However, if $\mathrm{Hb}$ variants affect the capacity of the $\mathrm{Hb}$ molecule to be glycated or if there are factors affecting erythrocyte turnover, the results will be inaccurate regardless of the $\mathrm{Hb}$ based method used $[2,7]$.

Hb Himeji [9] was first described in 1986 in a Japanese male with diabetes mellitus [11] and subsequently in two Japanese families and in two members of a Portuguese family $[10,12,13]$. To the best of our knowledge, these are the only reports dealing with this pathologic condition. This abnormal $\mathrm{Hb}$ results from a mutation in heterozygosity characterized by the substitution of alanine for the aspartic acid at position 141 (140 in the old nomenclature) of the $\beta$ chain of $\mathrm{Hb}$ [9]. Hb Himeji is a fast-moving $\mathrm{Hb}$ variant with an increased oxygen affinity, a mild molecular instability, and an increased glycation of the $\mathrm{NH}_{2}$ terminus of the $\beta$ chain [11-13].

The HbA1c measurement may be falsely low or high depending on the assay method because of various mechanisms (differences in HPLC mobility, increased glycation, antigenic changes of the variant $\beta$ chain, among others) [10]. We believe that the main factor for falsely low values of HbA1c in our patient was a reduced erythrocyte lifespan, with subsequent reticulocytosis. Electrospray ionization mass spectrometry (ESI-MS) is considered the most reliable method, but its excessive cost makes its use unlikely $[7,10]$. Commercial assays that measure glycated serum proteins (fructosamine) or glycated serum albumin can accurately reflect glycemic control of patients with diabetes with $\mathrm{Hb}$ Himeji $[2,7,14]$. However, these assays translate the mean 


\begin{tabular}{|c|c|c|c|r|}
\hline Peak Name & $\begin{array}{c}\text { Calibrated } \\
\text { Area 8 }\end{array}$ & Area 8 & $\begin{array}{c}\text { Retention } \\
\text { Time (min) }\end{array}$ & $\begin{array}{c}\text { Peak } \\
\text { Area }\end{array}$ \\
\hline Unknown & --- & 0.2 & 0.61 & 7251 \\
\hline Unknown & --- & 6.6 & 0.90 & 206295 \\
\hline F & $2.9 *$ & --- & 1.05 & 90047 \\
\hline Unknown & --- & 1.5 & 1.18 & 48564 \\
\hline P2 & --- & 2.5 & 1.32 & 79485 \\
\hline P3 & --- & 0.7 & 1.57 & 21441 \\
\hline Unknown & --- & 32.8 & 1.94 & 1028475 \\
\hline Ao & --- & 49.8 & 2.39 & 1562570 \\
\hline A2 & 2.7 & --- & 3.59 & 91518 \\
\hline
\end{tabular}

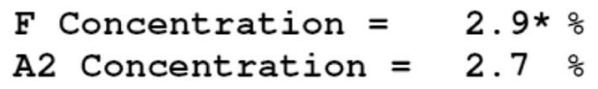

*Values outside of expected ranges

Analysis comments:

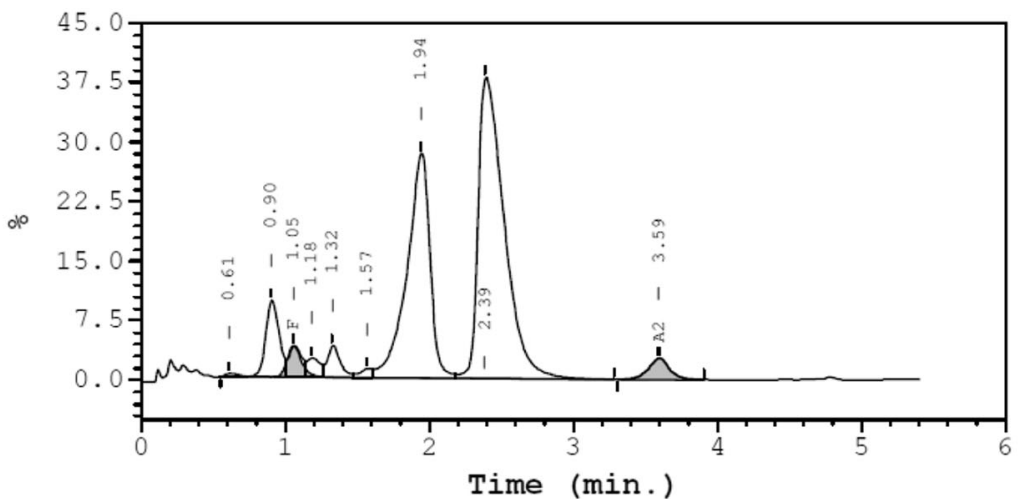

Fig. 1 High-performance liquid chromatography analysis with Bio-Rad variant II - beta-thal short program. An abnormal peak of 32.8\% was detected, with an earlier retention time than for $\mathrm{AO}$

glycemia over a period of only 2 weeks and neither test has been correlated with the risk for chronic diabetes complications $[1,2,7,10]$. Self-monitoring of blood glucose (SMBG) or continuous glucose monitoring also play an important role in assessing the efficacy of treatment and can be weighted in these cases [4].

Most patients with $\mathrm{Hb}$ Himeji are unaware of its presence, since they are asymptomatic [9]. However, they can have increased hemolysis and decreased erythrocyte survival. As such, in hematological stress situations, the compensatory reticulocytosis, observed in this patient, may be inadequate or absent and anemia can arise more easily and with greater severity than in normal situations [15]. In addition, HbA1c cannot be used to diagnose diabetes under conditions associated with increased red blood cell turnover [4]. To the best of our knowledge, Hb Himeji, by itself, is not associated with an increased risk of diabetesrelated complications. However, insufficient treatment, which may result from the exclusive use of the HbA1c value for monitoring glycemic control, may lead to the development of these complications. The control of other cardiovascular risk factors, namely blood pressure, lipid profile, body weight, and tobacco smoking, as well as the adoption of a healthy lifestyle, may explain the absence of microvascular or macrovascular complications in this patient [16]. Since there are few cases of Hb Himeji in patients with diabetes, we do not know if these patients have any other protective factor for diabetic complications that could be expected after 15 years of poor diabetic control.

\section{Conclusions}

Despite the advantages of HbA1c in the follow-up and treatment of diabetes, the factors that interfere with its results must be known, to ensure a correct estimation of the degree of glycemic control and a proper management of the disease. Therefore, health professionals should suspect the existence of $\mathrm{Hb}$ variants when: the HbA1c value is above $15 \%$ or below the lower limit of its reference interval; there is a significant modification in its result coinciding with a change in assay methods; and there is a low correlation between FPG/SMBG and HbA1c $[2,7,8]$. 


\section{Abbreviations}

DCCT: Diabetes Control and Complications Trial; ESI-MS: Electrospray ionization mass spectrometry; FPG: Fasting plasma glucose; Hb: Hemoglobin; HbA1c: Hemoglobin A1c; HPLC: High-performance liquid chromatography; NGSP: National Glycohemoglobin Standardization Program; SMBG: Selfmonitoring of blood glucose.

\section{Acknowledgements}

Not applicable.

\section{Funding}

The blood collection and testing of family members of the patient was supported by Associação dos Amigos do Serviço de Endocrinologia do Centro Hospitalar de São João.

\section{Availability of data and materials}

The datasets used and analyzed during the current study are available from the corresponding author on reasonable request.

\section{Authors' contributions}

VG and MLE diagnosed the patient and provided clinical information. VG, MLE, RBS, and MJT collected and analyzed the family data. VG, RBS, and MJT contributed in writing the manuscript. All authors reviewed and approved the final manuscript.

\section{Authors' information}

VG is currently a family medicine resident at Unidade de Saúde Familiar Faria Guimarães, Porto, Portugal. RBS is currently endocrinology resident at Centro Hospitalar de São João. MLE is an attending family medicine at Unidade de Saúde Familiar Egas Moniz, Santa Maria da Feira, Portugal. MJT is an attending clinical pathologist and JQ is an attending endocrinologist at Centro Hospitalar de São João. DC is currently the director of the endocrinology department at Centro Hospitalar de São João.

\section{Ethics approval and consent to participate}

Our Institutional Review Board approved the search of electronic medical records for this paper. The patients involved gave consent for the use of their medical records.

\section{Consent for publication}

Written informed consent was obtained from the patient for the publication of this case report and any accompanying images. A copy of the written consent is available for review by the Editor-in-Chief of this journal.

\section{Competing interests}

The authors declare that they have no competing interests.

\section{Publisher's Note}

Springer Nature remains neutral with regard to jurisdictional claims in published maps and institutional affiliations.

\section{Author details}

${ }^{1}$ Family Medicine, Unidade de Saúde Familiar Faria Guimarães, Rua Faria Guimarães 915/931, 4200-292 Porto, Portugal. ²Department of Endocrinology, Diabetes and Metabolism, Centro Hospitalar de São João E.P.E, Porto, Portugal. ${ }^{3}$ Faculty of Medicine, Instituto de Investigação e Inovação em Saúde, University of Porto, Porto, Portugal. ${ }^{4}$ Family Medicine, Unidade de Saúde Familiar Egas Moniz, Santa Maria da Feira, Portugal. ${ }^{5}$ Department of Clinical Pathology, Centro Hospitalar de São João E.P.E, Porto, Portugal.

Received: 8 February 2017 Accepted: 2 July 2017

Published online: 26 July 2017

\section{References}

1. Goldstein DE, Little RR, Lorenz RA, Malone JI, Nathan D, Peterson CM, Sacks DB. Tests of glycemia in diabetes. Diabetes Care. 2004;27:1761-73.

2. Sacks DB, Arnold M, Bakris GL, Bruns DE, Horvath AR, Kirkman MS, Lernmark A, Metzger BE, Nathan DM, National Academy of Clinical Biochemistry; Evidence-Based Laboratory Medicine Committee of the American Association for Clinical Chemistry. Guidelines and recommendations for laboratory analysis in the diagnosis and management of diabetes mellitus. Diabetes Care. 2011;34 e61-99.

3. Nathan DM, Kuenen J, Borg R, Zheng H, Schoenfeld D, Heine RJ, A1c-Derived Average Glucose Study Group. Translating the A1C assay into estimated average glucose values. Diabetes Care. 2008;31:1473-8.

4. American Diabetes Association. Standards of Medical Care in Diabetes - 2017. Diabetes Care. 2017;40 Suppl. 1:S1-S135.

5. National Glycohemoglobin Standardization Program Web Site. www.ngsp. org/. Accessed 15 Jan 2017.

6. World Health Organization. Use of glycated haemoglobin ( $\mathrm{HbA1c}$ ) in the diagnosis of diabetes mellitus. Abbreviated Report of a Who Consultation. Geneva: World Health Organization; 2011. p. 1-25.

7. Bry L, Chen PC, Sacks DB. Effects of hemoglobin variants and chemically modified derivatives on assays for glycohemoglobin. Clin Chem. 2001;47: 153-63.

8. Smaldone A. Glycemic Control and Hemoglobinopathy: When A1C May Not Be Reliable. Diabetes Spectrum. 2008:21:46-9.

9. Globin Gene Server. http://globin.cse.psu.edu/. Accessed 15 Jan 2017.

10. Nishihara E, Koga M, Kadowaki S, Murakami M, Harano K, Ito M, Kubota S, Amino $\mathrm{N}$, Miyauchi A. Method-dependent $\mathrm{HbA1c}$ values in a family with hemoglobin Himeji. Clin Chim Acta. 2011;412:1689-92.

11. Ohba Y, Miyaji T, Murakami M, Kadowaki S, Fujita T, Oimomi M, Hatanaka H, Ishikawa K, Baba S, Hitaka K. Hb Himeji or beta 140 (H18) Ala_—Asp. A slightly unstable hemoglobin with increased beta N-terminal glycation. Hemoglobin. 1986;10:109-25

12. Lavinha J, Faustino P, Osório-Almeida L, Hattori Y, Ohba Y, Martins MC. Hb Himeji [alpha 2 beta 2(140)(H18)Ala_- Asp] is linked to different haplotypes in Japanese and Portuguese families. Hemoglobin. 1991;15:137-8.

13. Martins MC, Rosado L, Wilson JB, Kutlar A, Hu H, Huisman TH. Hb Himeji or alpha 2 beta 2(140)(H18)Ala_—Asp in a Portuguese family. Hemoglobin. 1989;13:411-5.

14. Speeckaert M, Van Biesen W, Delanghe J, Slingerland R, Wiecek A, Heaf J, Drechsler C, Lacatus R, Vanholder R, Nistor I, European Renal Best Practice Guideline Development Group on Diabetes in Advanced CKD. Are there better alternatives than haemoglobin A1c to estimate glycaemic control in the chronic kidney disease population? Nephrol Dial Transplant. 2014;29: 2167-77.

15. Barcellini W, Fattizzo B. Clinical Applications of Hemolytic Markers in the Differential Diagnosis and Management of Hemolytic Anemia. Dis Markers. 2015;2015:635670.

16. Hayes AJ, Leal J, Gray AM, Holman RR, Clarke PM. UKPDS outcomes model 2: a new version of a model to simulate lifetime health outcomes of patients with type 2 diabetes mellitus using data from the 30 year United Kingdom Prospective Diabetes Study: UKPDS 82. Diabetologia. 2013;56:1925-33.

\section{Submit your next manuscript to BioMed Central and we will help you at every step:}

- We accept pre-submission inquiries

- Our selector tool helps you to find the most relevant journal

- We provide round the clock customer support

- Convenient online submission

- Thorough peer review

- Inclusion in PubMed and all major indexing services

- Maximum visibility for your research

Submit your manuscript at www.biomedcentral.com/submit
Biomed Central 